\title{
Melhoria da gestão escolar através do uso de técnicas de mineração de dados educacionais: um estudo de caso em escolas municipais de Maceió
}

Olival de Gusmão Freitas Júnior ${ }^{1}$, Wanderson Rubian Martins Rodrigues ${ }^{1}$, João Carlos Cordeiro Barbirato $^{1}$, Evandro de Barros Costa ${ }^{1}$

${ }^{1}$ Instituto de Computação - Universidade Federal de Alagoas (UFAL) - AL - Brasil

\{olival@ic.ufal.br, rubian64@gmail.com, jccb@ctec.ufal.br, evandro@ic.ufal.br\}

Resumo. Este artigo tem como objetivo utilizar uma ferramenta de mineração de dados, para analisar o Índice de Desenvolvimento da Educação Básica (IDEB) das escolas públicas do município de Maceió, visando auxiliar no processo decisório dos gestores educacionais pela adoção de medidas de melhoria da gestão escolar. Utilizam-se os dados educacionais das escolas públicas de Maceió coletados do portal do INEP, principalmente, das informações dos questionários aplicados aos alunos que realizaram a Prova Brasil. Neste trabalho, utilizou-se duas técnicas de mineração de dados: regressão linear e árvore de decisão, visando identificar fatores que influenciam no desempenho do IDEB. Os resultados indicam que diversos fatores influenciam o desempenho do aluno, tais como: a escolaridade dos pais do aluno, o incentivo aos estudos e o compromisso do docente.

Palavras-chave: Índice de Desenvolvimento da Educação Básica (IDEB), CRISP-DM, Mineração de dados educacionais, Metodologia para predição de indicadores.

\section{Improving school management through the use of educational data mining techniques: a case study in municipal schools of Maceió}

\begin{abstract}
This article aims to use a data mining tool to analyze the Basic Education Development Index (IDEB) of public schools in the city of Maceió, aiming to assist in the decision-making process of educational managers to adopt measures to improve IDEB. It is used educational data from public schools in Maceió collected from INEP portal as well as information from questionnaires given to students who underwent Prova Brasil. In this work, two techniques of data mining were used: linear regression and decision tree, aiming at identifying factors that directly influence IDEB's performance. The results indicate that several factors influence the performance of the student such as: schooling of the student's parents, encouragement of studies and the commitment of the teacher.
\end{abstract}

Keyword: Index of Basic Education Development (IDEB), CRISP-DM, Educational data mining, Methodology for predicting indicators.

\section{Introdução}

Há cada vez mais necessidade de informação de qualidade por parte dos gestores educacionais, visando à efetividade na tomada de decisões no sentido de melhorar o processo de ensino e aprendizagem nas instituições educacionais públicas do Brasil. Observando esse cenário, o Ministério da Educação criou o Índice de Desenvolvimento da Educação Básica (IDEB) para avaliar o processo de ensino e aprendizagem nas escolas brasileiras. Esse índice tem sido influenciado por vários fatores educacionais, presentes nas escolas oriundos de avaliações sobre o aproveitamento escolar dos alunos, por meio do censo escolar e as médias de desempenho nas avaliações do Sistema de 
Avaliação da Educação Básica, a Prova Brasil, a Avaliação Nacional de Alfabetização entre outras (IDEB, 2016; INEP/MEC, 2007; INEP, 2016).

Os dados armazenados nesses ambientes educacionais constituem fontes de informação que podem ser analisadas por meio da mineração de dados. A área da mineração de dados vem sendo muito utilizada na ciência da computação para descobrir padrões ou tendências em grandes bases de dados. Atualmente vem sendo utilizada e aplicada na área da educação para tratamento dos dados educacionais, visando à melhoria na gestão educacional, na organização do trabalho pedagógico e na melhoria da qualidade do ensino e da aprendizagem (PAIVA et al., 2012).

A mineração de dados educacionais (MDE) é um campo de pesquisa que busca descobrir padrões ou evidências sobre estudantes e formas de aprendizagem. Nos últimos anos diversos trabalhos (Coelho et al., 2015; Manhães, 2015) têm explorados os benefícios que o MDE traz ao ambiente educacional.

Neste trabalho, resolveu-se utilizar uma ferramenta de mineração de dados, para analisar o IDEB das escolas públicas e trabalhar com diferentes atributos com a utilização de algoritmos que podem fornecer resultados significativos para a melhoria da gestão escolar. Buscou-se responder como técnicas de mineração de dados podem ser utilizadas na MDE, a partir da classe IDEB e outros atributos para contribuir na reflexão da melhoria da gestão e do processo de ensino e aprendizagem das escolas municipais de Maceió.

Este artigo tem como objetivo geral explorar técnicas de mineração de dados educacionais em escolas públicas do município de Maceió-Alagoas, visando encontrar os fatores (atributos) responsáveis pela melhoria do desempenho escolar, visando auxiliar no processo decisório dos gestores educacionais para adotar medidas de melhoria do IDEB.

Trata-se de uma pesquisa de cunho quantitativa e exploratória. Do ponto de vista dos procedimentos técnicos, trata-se de um estudo de caso. Iniciou-se a pesquisa do tipo estudo de caso, em que foi evidenciada a análise dos dados educacionais de 80 escolas públicas municipais de Maceió, referente apenas aos anos inicias do ensino fundamental $\left(1^{\circ}\right.$ ao $\left.5^{\circ}\right)$, a partir de uma pesquisa no portal do INEP. Convém ressaltar que este portal apresenta os dados educacionais de diversos anos, mas com foco no Índice de Desenvolvimento da Educação Básica das instituições que realizaram a Prova Brasil.

O artigo está organizado da seguinte forma: a seção 2 abordará alguns trabalhos relacionados a esta temática, tentando mostrar a originalidade do presente trabalho. A seção 3 tratará sobre a metodologia CRISP-DM seguida no trabalho, destacando as suas seis etapas. A seção 4 apresenta as conclusões obtidas com este trabalho.

\section{Trabalhos relacionados}

Neste tópico são apresentados alguns trabalhos relacionados a esta temática, assim como suas respectivas formas de abordagem. Nos últimos anos várias pesquisas relacionadas a tópicos de Mineração de Dados Educacionais (MDE) vêm sendo realizadas.

Nascimento et al (2018) aplicou técnicas de MDE com a finalidade de explicar indicadores como a evasão e reprovação escolar no ensino fundamental. Os modelos foram desenvolvidos utilizando as técnicas de regressão linear e robusta, sendo avaliados pelo erro médio absoluto, desvio padrão e gráficos. Os resultados indicaram que a regressão robusta obteve melhores resultados nas variáveis elencadas nesse estudo. 
Filho e Adeodato (2017) apresentaram uma solução de MDE para predição e estimação do desempenho dos alunos do ensino médio dos Institutos Federais, verificando propensão ao insucesso acadêmico por parte dos alunos.

Bezerra et al (2016) abordou a evasão escolar no último ano do ensino fundamental nas escolas públicas estaduais e municipais do estado de Pernambuco, com base nos dados dos Censos Escolares 2011 e 2012. Utilizou-se de técnicas de mineração de dados para identificar o perfil do aluno evadido e estimar a propensão à evasão.

Manhães (2015) apresentou uma proposta de arquitetura baseada em MDE que oferecia informações úteis sobre o desempenho acadêmico dos graduandos e predizia os que estão em risco de abandonar o sistema de ensino por meio da predição do seu desempenho acadêmico. Por outro lado, Coelho et al. (2015) abordou a MDE aplicada à educação a distância, focando-se na busca e análise de indicadores que contribuam para uma melhor visualização e monitoramento do ambiente virtual de aprendizagem, auxiliando assim a criação de ações direcionadas e mais efetivas com o intuito de favorecer o uso e acessibilidade ao público da Escola Virtual da ENAP.

Márquez-Vera et al (2013) aplicou de técnicas de MDE no data set de 670 alunos do ensino médio de Zacatelas (México) para descrever o insucesso escolar através da identificação de quais alunos poderiam evadir. Com isso, algumas ações preventivas poderiam ser tomadas para evitar a evasão escolar desses alunos.

O presente artigo tem como foco o melhoramento da gestão educacional e do processo de ensino e aprendizagem em escolas públicas de ensino fundamental (anos iniciais), por meio da utilização da ferramenta de mineração de dados (WEKA) em dados de 80 escolas municipais da cidade de Maceió-Alagoas, cruzando o IDEB dessas escolas com informações extraídos do portal do INEP, para posteriores estudos e reflexões na área da educação. Analisando as diversas abordagens dos trabalhos consultados, torna-se mais evidente que o presente foco exclusivo nas instituições educacionais municipais de ensino básico ainda não havia sido explorado.

\section{Metodologia}

Uma das metodologias mais populares para aumentar o sucesso dos processos de mineração de dados é o CRISP-DM. Essa metodologia define uma sequência não rígida de seis etapas, que permite a construção e implementação de um modelo de mineração para ser usado em um ambiente real, auxiliando as decisões de negócio (Chapman et al., 2000). Dessa forma, o desenvolvimento deste trabalho seguiu as etapas do CRISP-DM, apresentada na Figura 1 sendo descritas a seguir.

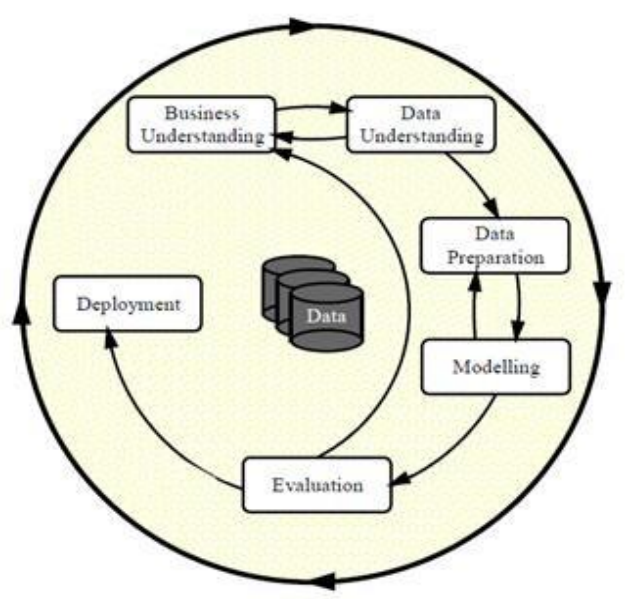

Figura 1. Etapas da metodologia CRISP-DM. Fonte: Chapman et al. (2000) 
$1^{a}$ Etapa: Compreensão do domínio. Esta etapa foca no conhecimento dos objetivos do projeto e, então, converte-se esse conhecimento em uma definição de problema de mineração de dados e um plano de projeto preliminar com a intenção de alcançar os objetivos. Nesta etapa, além de definir os objetivos a serem alcançados, determinam-se os critérios de sucesso do projeto. Também serão definidos os recursos necessários à execução de todo o plano de mineração. O objetivo do projeto, nesse caso, é encontrar os fatores (atributos) responsáveis pela melhoria do desempenho escolar, visando auxiliar no processo decisório dos gestores educacionais para adotar medidas de melhoria do IDEB. Este estudo fará a análise dos dados educacionais de 80 escolas públicas municipais de Maceió dos anos iniciais do ensino fundamental. Segundo o MEC (2018), o IDEB no ano de 2017 para os anos iniciais da rede pública de Maceió cresceu e atingiu a meta, alcançando 5,6 (Tabela 1).

Tabela 1. Metas para a educação básica de Alagoas.

\begin{tabular}{cccccccccccc}
\hline & \multicolumn{1}{c}{ IDEB Observado } & \multicolumn{6}{c}{ Metas } \\
\hline & $\mathbf{2 0 0 9}$ & $\mathbf{2 0 1 1}$ & $\mathbf{2 0 1 3}$ & $\mathbf{2 0 1 5}$ & $\mathbf{2 0 1 7}$ & $\mathbf{2 0 0 7}$ & $\mathbf{2 0 0 9}$ & $\mathbf{2 0 1 1}$ & $\mathbf{2 0 1 3}$ & $\mathbf{2 0 1 5}$ & $\mathbf{2 0 1 7}$ \\
\hline Total & 4.6 & 5.0 & 5.2 & 5.5 & 5.8 & 3.9 & 4.2 & 4.6 & 4.9 & 5.2 & 5.5 \\
\hline & & & & & & & & & & & \\
\hline Estadual & 4.9 & 5.1 & 5.4 & 5.8 & 6.0 & 4.0 & 4.3 & 4.7 & 5.0 & 5.3 & 5.6 \\
\hline Municipal & 4.4 & 4.7 & 4.9 & 5.3 & $\mathbf{5 . 6}$ & 3.5 & 3.8 & 4.2 & 4.5 & 4.8 & $\mathbf{5 . 1}$ \\
\hline Privada & 6.4 & 6.5 & 6.7 & 6.8 & 7.1 & 6.0 & 6.3 & 6.6 & 6.8 & 7.0 & 7.2 \\
\hline Pública & 4.4 & 4.7 & 4.9 & 5.3 & 5.5 & 3.6 & 4.0 & 4.4 & 4.7 & 5.0 & 5.2 \\
\hline & & \multicolumn{1}{c}{ Fonte: MEC (2018) } & & & & &
\end{tabular}

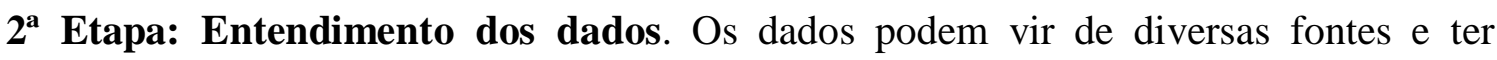
diversos formatos. Esta é a etapa de familiarização com os dados do problema e identificação da qualidade dos mesmos, bem como pela construção das primeiras percepções e indagações sobre o que os dados podem mostrar (PÁDUA E SOUSA, 2018). As bases de dados usadas nesse estudo foram disponibilizadas abertamente pelo portal do INEP. Segundo o INEP (2016), o questionário do aluno dos anos iniciais do ensino fundamental consiste de 58 itens, distribuídos em 6 (seis) categorias conforme o Quadro 1.

\begin{tabular}{|c|c|}
\hline Categoria & Descrição \\
\hline Caracterização sociodemográfica & Sexo, cor, raça e idade \\
\hline Informações socioeconômicas & Capital econômico \\
\hline Capital social & $\begin{array}{l}\text { Convívio, formação e atitude dos pais ou responsáveis } \\
\text { na educação do aluno }\end{array}$ \\
\hline Capital cultural & Hábitos de leitura e gestão do tempo \\
\hline Trajetória escolar & $\begin{array}{l}\text { Tempo de permanência na escola, reprovação e } \\
\text { abandono }\end{array}$ \\
\hline Atitudes em relação a estudos específicos & $\begin{array}{l}\text { Atitudes do aluno e do professor em relação ao estudo } \\
\text { de português e matemática, somados a um item sobre } \\
\text { uso da biblioteca ou sala de leitura }\end{array}$ \\
\hline
\end{tabular}

Fonte: Adaptado de INEP (2016)

$3^{\text {a }}$ Etapa: Preparação dos dados. Esta etapa tem o objetivo de construir o conjunto final de dados que serão utilizados nas ferramentas de modelagem. As tarefas de 
preparação podem ser realizadas muitas vezes, e sem uma ordem pré-determinada. Esta etapa envolve operações como tratar a falta de dados em alguns campos, limpeza de dados como a verificação de inconsistências, redução da quantidade de campos em cada registro, o preenchimento ou a eliminação de valores nulos, remoção de dados duplicados. Coletou-se os dados educacionais das 80 escolas selecionadas no portal do INEP. Tanto para a coleta, quanto para o pré-processamento dos dados utilizou-se o MS Excel 2003. Consultou-se um especialista em gestão educacional para selecionar as questões mais relevantes da prova Brasil. Segue a Tabela 2 com os atributos escolhidos e sua representação na ferramenta WEKA.

Tabela 2. Questões e seus correspondentes atributos na ferramenta WEKA.

\begin{tabular}{ll}
\hline Questões da Prova Brasil & Atributos (WEKA) \\
\hline Sexo & Masculino, Feminino \\
\hline Qual a sua idade? & 8 anos, 9 anos, 10 anos... \\
\hline Na sua casa possui computador? & Possui_Computador \\
\hline Até que série sua mãe ou a mulher responsável por você estudou? & Escolaridade_Mae \\
\hline Até que série seu pai ou o homem responsável por você estudou? & Escolaridade_Pai \\
\hline Seus pais ou responsáveis incentivam você a estudar? & Incentiva_a_Estudar \\
\hline Seus pais ou responsáveis incentivam você a fazer o dever de casa? & Incentiva_Dever_Casa \\
\hline Seus pais ou responsáveis incentivam você a ler? & Incentiva_a_Ler \\
\hline Seus pais ou responsáveis incentivam você a ir à escola e não faltar às & Incentiva_ir_escola \\
aulas? & Ler_Livro \\
\hline Você lê livros em geral? & Freq_Biblioteca \\
\hline Você costuma frequentar bibliotecas? & Escola_Estudou \\
\hline Desde a primeira série em que tipo de escola você estudou? & Reprovacao \\
\hline Você já foi reprovado? & Evasao \\
\hline Você já abandonou a escola durante o período de aulas e ficou fora da \\
escola o resto do ano? & Dever_Portugues \\
\hline Você faz o dever de casa de língua portuguesa? & Corrige_Portugues \\
\hline O professor corrige o dever de casa de língua portuguesa? & Dever_Matematica \\
\hline Você faz o dever de casa de matemática? & Corrige_Matematica \\
\hline O professor corrige o dever de casa de matemática? & Biblioteca_Salaleitura \\
\hline Você utiliza a biblioteca ou sala de leitura da sua escola? & Infraestrutura \\
\hline Censo & \\
\hline
\end{tabular}

Fonte: Dos autores.

Nesta etapa alguns atributos passaram por um processo de discretização, ou seja, foram transformados em outros valores que correspondem à mesma informação. Essa estratégia é usada para descobrir mais informações sobre os dados, uma vez que a variável contínua não permite isso. Como exemplo, pode-se citar a feature idade que corresponde uma faixa de idade para verificar a distorção idade-série. Ao se identificar essa distorção cria-se um novo campo na tabela de dados, isso permite verificar o impacto da distorção idade-série no IDEB.

$4^{\text {a }}$ Etapa: Modelagem. Nesta etapa, várias técnicas de modelagem são selecionadas e aplicadas. Tipicamente, existem diversas técnicas para o mesmo tipo de problema de mineração. No entanto, há algumas que dependem do objetivo desejado. A escolha do pacote WEKA para realização do trabalho deu-se em virtude de sua facilidade de uso, bem como da disponibilização de diversos algoritmos que implementam técnicas de data mining. Nesta etapa buscou-se priorizar duas técnicas de utilização dos algoritmos, a saber: a técnica de mineração por regressão linear simples e a técnica de mineração por árvore de decisão (J48).

Para a realização dos testes foi usado o algoritmo de Regressão Linear Simples (função SimpleLinearRegression da ferramenta WEKA), o qual utilizou apenas o atributo classe IDEB e o atributo no qual está sendo realizada sua correlação, removendo no WEKA todos os atributos e mantendo apenas estes dois. Realizou-se este 
teste com cada atributo individualmente e obteve-se os modelos de regressão e valores de correlação observado na Tabela 3.

Tabela 3. Modelo de regressão e coeficiente dos 20 atributos mais relevantes.

\begin{tabular}{ll} 
Atributo & Coeficiente de correlação \\
\hline Incentiva dever de casa & 0.5477 \\
\hline Média de incentivo & 0.5102 \\
\hline Idade de 14 anos & 0.4473 \\
\hline Escola que estudou & 0.4301 \\
\hline Evasão & 0.4043 \\
\hline Incentiva ir à escola & 0.3776 \\
\hline Corrige o dever de matemática & 0.3467 \\
\hline Escolaridade da mãe & 0.3355 \\
\hline Incentiva a leitura & 0.3307 \\
\hline Média da escolaridade dos pais & 0.3263 \\
\hline Idade de 13 anos & 0.2912 \\
\hline Incentiva a estudar & 0.2739 \\
\hline Sexo masculino & 0.2703 \\
\hline Sexo feminino & 0.2703 \\
\hline Média dever corrigido & 0.2559 \\
\hline Escolaridade do pai & 0.2418 \\
\hline Idade de 10 anos & 0.2346 \\
\hline Infraestrutura & 0.1870 \\
\hline Idade de 8 anos & 0.1753 \\
\hline Frequência a Biblioteca & 0.1705 \\
\hline & \\
\hline
\end{tabular}

Fonte: Dos autores.

Nessa análise foram considerados todos os atributos e realizado a sua influência em relação ao IDEB. Com esses resultados, pode-se analisar a influência de cada atributo na construção do IDEB, visando avaliar uma possível dependência de Y (atributo classe IDEB) em X (demais atributos), os valores do coeficiente de correlação apresentam o quão boa é a correlação. No modelo de regressão é observado se a correlação é positiva ou negativa, ou seja, se o fator contribui positivamente ou negativamente no IDEB.

A Figura 2 mostra a representação gráfica da correlação entre os atributos " $\mathrm{X}$ : MEDIA_INCENTIVO" (linha horizontal) e "Y: IDEB_2011" (linha vertical). Nela é possível perceber a correlação entre esses dois atributos. É possível observar os 80 pontos que representam cada uma das instâncias (escolas), em sua grande maioria localizadas na parte superior direita, evidenciando o quanto o incentivo aos estudos ajuda na melhoria do IDEB. 


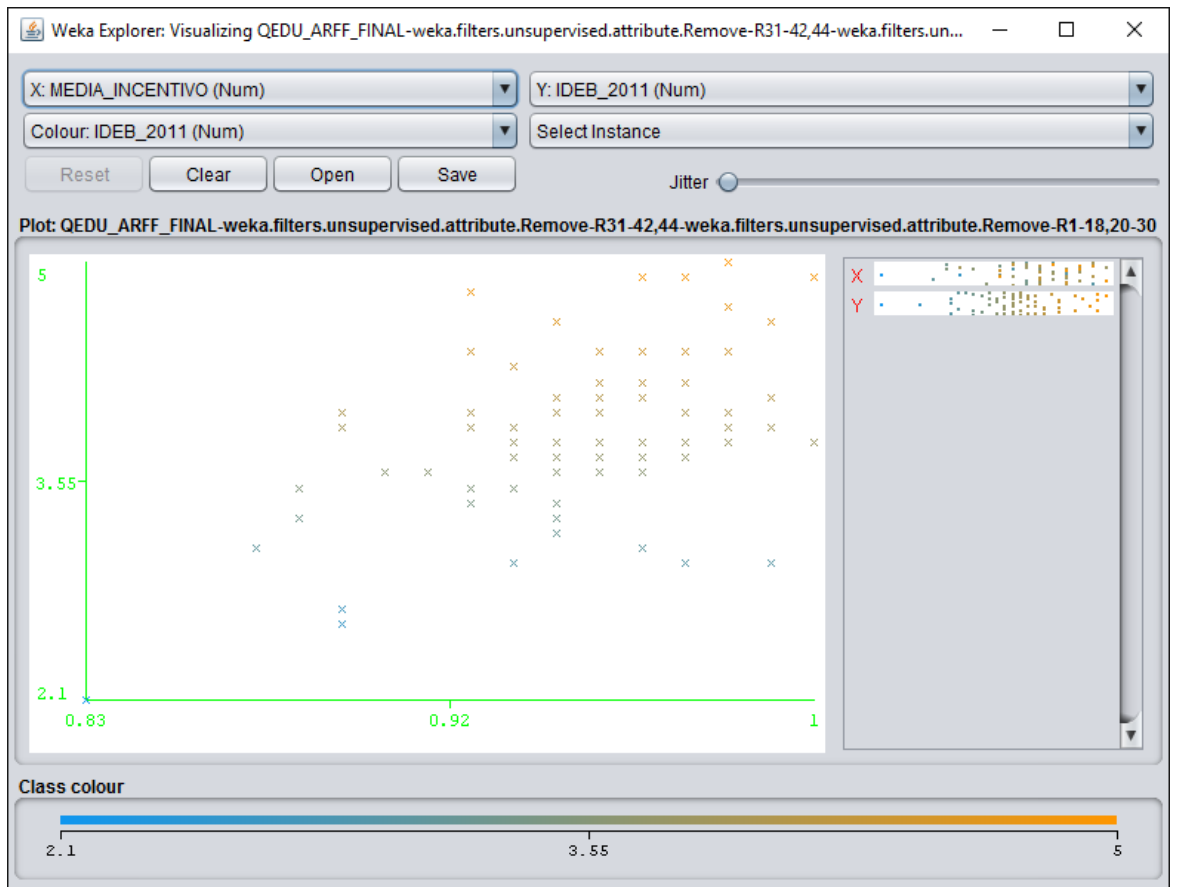

Figura 2. Visualização do algoritmo de regressão linear no WEKA. Fonte: Dos autores.

Para a realização dos testes com o algoritmo de classificação J48, utilizou-se a base de dados com todos os atributos, porém com uma pequena alteração no atributo classe, que foi necessário ser categorizado, esta etapa de discretização se faz necessária para se trabalhar com o algoritmo J48. É importante ressaltar que os algoritmos de classificação requerem que os dados estejam na forma de atributos categorizados. Mantiveram-se as configurações padrões do algoritmo J48 na ferramenta WEKA. Com esse resultado obteve-se uma árvore que pode ser visualizada graficamente pela Figura 3.

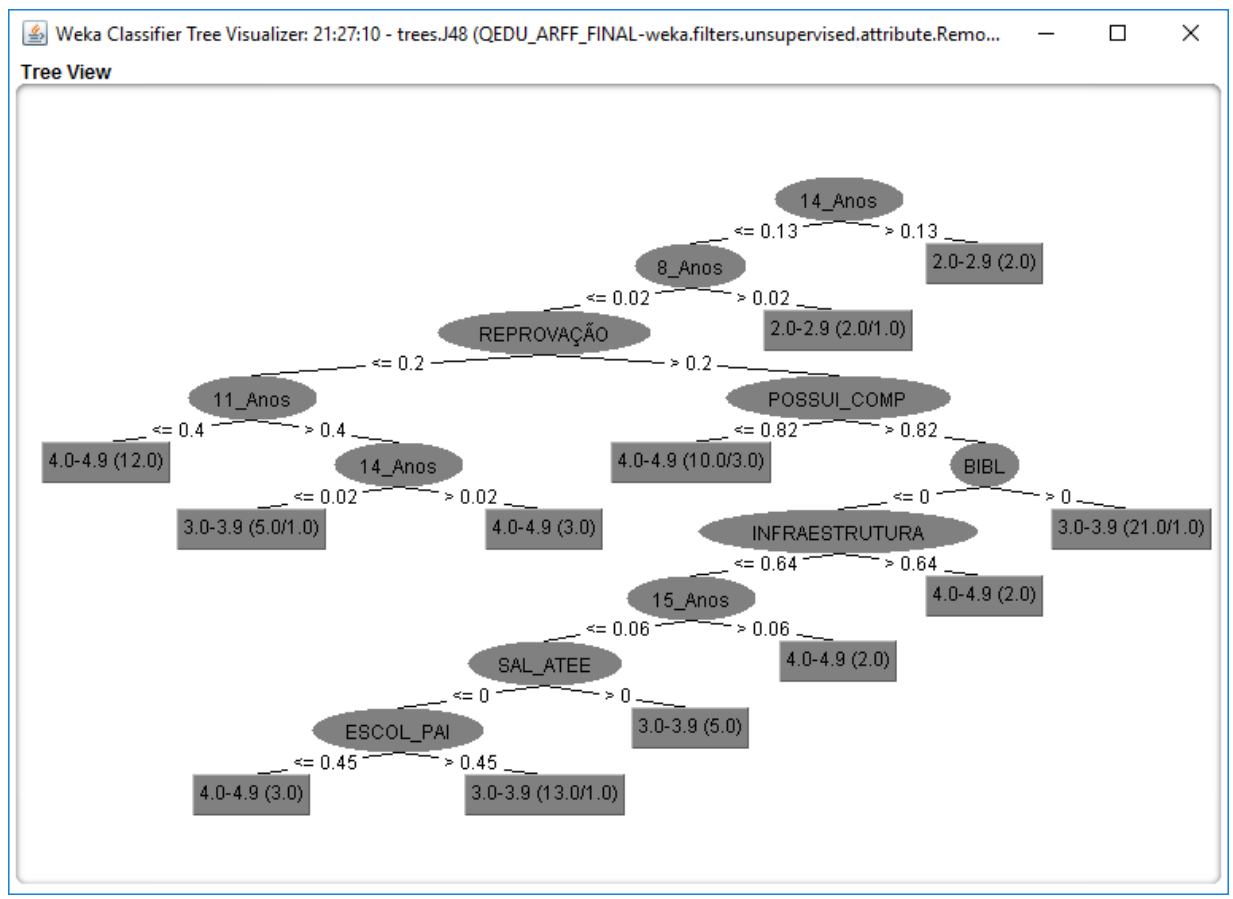

Figura 3. Visualização da árvore de decisão J48 do WEKA.

Fonte: Dos autores. 
Analisando a Figura 3, percebeu-se que infraestrutura não tem muita relevância no IDEB. Notou-se, ainda, através da análise da árvore de decisão, que a melhoria do IDEB está diretamente ligada as ações pedagógicas dos professores em sala de aula e da gestão escolar.

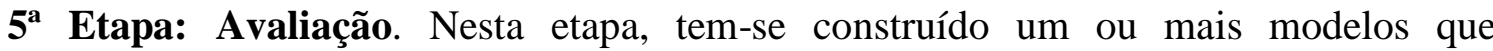
aparentam ter alta qualidade. Ao final será tomada uma decisão a partir dos resultados da mineração, sem, entretanto, desconsiderar alguma questão que seja importante (PÁDUA E SOUSA, 2018). Esta é a etapa no qual os conhecimentos encontrados são interpretados e utilizados em processo decisório. Com base nas análises efetuadas, pode-se apontar para as conclusões do Quadro 2.

Quadro 2. Dimensões e atributos relevantes para o IDEB segundo os algoritmos.

\begin{tabular}{|c|c|c|}
\hline Dimensão & Atributo & Reflexão sobre o IDEB \\
\hline \multirow[t]{6}{*}{ Discente } & Sexo & $\begin{array}{l}\text { Percebe-se que os discentes do sexo feminino têm um } \\
\text { destaque maior na melhoria do IDEB. }\end{array}$ \\
\hline & $\begin{array}{l}\text { Distorção entre } \\
\text { idade-série }\end{array}$ & $\begin{array}{l}\text { Os alunos que estão na faixa correta com relação à idade e } \\
\text { série ( } 9 \text { a } 12 \text { anos) contribuem positivamente no IDEB. } \\
\text { Todavia, os alunos que se encontram na faixa errada com } \\
\text { relação à idade e série ( } 8 \text { anos ou de } 13 \text { anos ou mais) } \\
\text { contribuem de forma negativa no IDEB. }\end{array}$ \\
\hline & $\begin{array}{l}\text { Trajetória escolar } \\
\text { (evasão) }\end{array}$ & $\begin{array}{l}\text { Alunos com altos índices de evasão contribuem } \\
\text { negativamente no IDEB. }\end{array}$ \\
\hline & $\begin{array}{l}\text { Informações } \\
\text { socioeconômicas }\end{array}$ & $\begin{array}{l}\text { Observa-se que alunos que estudaram anteriormente em } \\
\text { escolas particulares contribuem de maneira expressiva na } \\
\text { melhoria do IDEB. }\end{array}$ \\
\hline & Escolaridade dos pais & $\begin{array}{l}\text { Percebe-se que a escolaridade dos pais exerce influência } \\
\text { positiva no IDEB. Todavia, apesar dos pais terem uma } \\
\text { escolaridade maior que as mães, ficou constatado que a mãe } \\
\text { possui maior influência no aprendizado do aluno. }\end{array}$ \\
\hline & Incentivo aos estudos & $\begin{array}{l}\text { Quanto à análise dos incentivos aos estudos, ficou claro que } \\
\text { é o fator que mais pesa para obtenção de um melhor IDEB. }\end{array}$ \\
\hline \multirow[t]{2}{*}{ Docente } & $\begin{array}{l}\text { Compromisso do } \\
\text { docente }\end{array}$ & $\begin{array}{l}\text { Observa-se que a cobrança maior por parte dos professores } \\
\text { nas disciplinas de língua portuguesa e matemática contribui } \\
\text { positivamente no IDEB, sendo que a disciplina de } \\
\text { matemática tem um peso ainda maior. }\end{array}$ \\
\hline & Formação do docente & $\begin{array}{l}\text { Nota-se que a formação adequada do docente interfere de } \\
\text { forma positiva no IDEB. Como formação adequada } \\
\text { considera-se docente com curso superior de licenciatura na } \\
\text { disciplina lecionada. }\end{array}$ \\
\hline Gestor & Estilo de gestão & $\begin{array}{l}\text { Observa-se que o estilo de gestão tem impactado no IDEB. } \\
\text { Um gestor que atua como um líder democrático e que realiza } \\
\text { uma gestão baseado em resultados contribui } \\
\text { significativamente para a melhoria do IDEB da sua unidade } \\
\text { escolar. }\end{array}$ \\
\hline Infraestrutura & $\begin{array}{l}\text { Infraestrutura em } \\
\text { geral (biblioteca, sala } \\
\text { de leitura, etc.) }\end{array}$ & $\begin{array}{l}\text { Ficou constatado que leituras de livros em geral, frequência à } \\
\text { biblioteca e a existência de biblioteca, sala de leitura e outras } \\
\text { questões de infraestrutura em geral nas escolas, não exercem } \\
\text { influência considerável no IDEB. Também ficou constatado } \\
\text { que à posse de computadores não causa grande interferência } \\
\text { no IDEB. }\end{array}$ \\
\hline
\end{tabular}

Fonte: Dos autores.

6 ${ }^{\mathbf{a}}$ Etapa: Distribuição. A criação do modelo não é o fim do projeto. Em alguns casos, o conhecimento adquirido precisará ser organizado e apresentado de uma forma que 
possa ser usado (PÁDUA E SOUSA, 2018). Conforme dito antes, o resultado do presente trabalho pode ser aplicado tanto em outros novos projetos, que porventura podem aparecer como nos objetivos inicialmente traçados. São os gestores educacionais os responsáveis pelo projeto que decidem se e de que maneira o conhecimento será utilizado. Esse estudo de caso serviu para perceber o quanto cada atributo influência na determinação da classe IDEB, influenciando, assim na melhoria dos índices nas escolas públicas do município de Maceió.

Com essa metodologia, pode-se obter informações importantes no âmbito educacional, que possa ser útil no processo decisório de gestores educacionais, visando à melhoria da gestão escolar.

\section{Conclusão}

Os resultados advindos do processamento dos dados na ferramenta WEKA proporciona uma espécie de provocação, pautando discussões interessantes na área pedagógica. Por exemplo, ao se considerar que foi constatado na análise dos dados tratados pelo WEKA que leituras de livros em geral, frequência à biblioteca e a existência de biblioteca, sala de leitura e outras questões de infraestrutura em geral nas escolas, não têm influência considerável no IDEB, suscita-se minimamente uma discussão entre o ter e o usar. Uma pergunta pode ser feita à equipe pedagógica (junto às escolas): como as unidades escolares estão utilizando esses equipamentos? A resposta pode ser surpreendente, a de que o uso pode não ser o mais adequado. Uma outra pergunta, então, poderia melhor qualificar o dado a ser processado. Por exemplo, ao invés de se trabalhar com ter livros ou biblioteca disponíveis, obter informações da quantidade de livros que um estudante lê de fato. Pode-se descobrir distorções importantes no fazer pedagógicos desses ambientes, e que passam despercebidos pela gestão (da secretaria e da unidade escolar).

Utilizou-se técnicas de regressão linear simples e de árvore de decisão (J48) para identificar os fatores que influenciavam o IDEB das escolas da Rede Municipal de Maceió. Buscou-se demonstrar que a MDE pode auxiliar os gestores a traçar ações que possam reduzir a taxa de evasão e reprovação escolar, por exemplo, melhorando com isso o IDEB na sua unidade escolar.

Os resultados obtidos com a aplicação da MDE poderão servir como indicativos para a direção das escolas públicas municipais no tocante ao auxílio ao processo decisório, principalmente no que se refere a investimentos, visando à melhoria no padrão do aprendizado, como consequência o aumento do IDEB.

Verifica-se que a ferramenta WEKA pode ser utilizada na MDE e contribuir no tratamento da informação a partir de atributos preestabelecidos na comunicação ou socialização dos conhecimentos oriundos dos questionários do INEP, ou de outro banco de dados disponível.

Neste trabalho junto às escolas da Rede Municipal de Maceió no tocante à análise de dados IDEB da educação básica, constatou-se uma lacuna epistemológica e que em futuros estudos poderia melhorar a capacidade e o domínio da ferramenta WEKA, podendo contribuir na melhoria do tratamento dos dados educacionais das escolas públicas. Como trabalhos futuros, pretende-se aplicar outros algoritmos de mineração de dados, expandir o escopo do estudo para outros níveis de escolaridade e para outros cenários como o estadual e nacional. 


\section{Referências}

BEZERRA, C.; SCHOLZ, R.; ADEODATO, P.; PONTES, T.; SILVA, I. (2016). Evasão Escolar: Aplicando Mineração de Dados para Identificar Variáveis Relevantes. V Congresso Brasileiro de Informática na Educação (CBIE 2016). Anais do XXVII Simpósio Brasileiro de Informática na Educação (SBIE 2016).

CHAPMAN, P. et al. (2000). CRISP-DM 1.0 step-by-step data mine guide. CRISPDM Consortium.

COELHO, V. C.; COSTA, J. P. C. L.; SOUSA, D. C. R.; CANEDO, E. D.; SILVA, D. G.; SOUSA JÚNIOR R. T. (2015). Mineração de dados educacionais para identificação de barreiras na utilização da educação a distância. Escola Nacional de Administração Pública. ENAP. Ministério do Planejamento, Orçamento e Gestão, Brasília -DF.

FILHO, R.L.C.S.; ADEODATO,P.J.L. (2017). Solução de Mineração de Dados para Avaliação do Ensino Médio dos Institutos Federais a partir do Censo Escolar e do Enem. 15 Conferências Ibero-Americanas WWW/Internet e computação aplicada 2017. Vilamoura, Algarve, Portugal.

IDEB. (2016). Índice de Desenvolvimento da Educação Básica. Disponível em: http://ideb.inep.gov.br/>. Acesso em: 10 de setembro de 2016.

INEP/MEC. (2007). Indicadores da Qualidade da Educação. São Paulo: ação educativa.

INEP. (2016). Prova Brasil. Sistema de Avaliação da Educação Básica (Saeb). Disponível em: http://provabrasil.inep.gov.br/>. Acessado em: 10 de setembro de 2016.

MANHÃES, L. M. B. (2015). Predição do desempenho acadêmico de graduandos utilizando mineração de dados educacionais. Tese (Doutorado em Engenharia de Sistemas e Computação. Universidade Federal do Rio de Janeiro. Rio de Janeiro.

MÁRQUEZ-VERA, C.; Morales, C. R.; Soto, S. V. (2013). Predicting School Failure and Dropout by Using Data Mining Techniques. IEEE Journal of Latin American Learning Technologies. Vol. 8, no. 1, February.

MEC. IDEB. (2018). Índice de Desenvolvimento da Educação Básica. Disponível em: http://ideb.inep.gov.br/>. Acessado em: 10 de setembro de 2018.

NASCIMENTO, R. L. S.; Cruz Junior, G. G; Fagundes, R. A. A. (2018). Mineração de Dados Educacionais: Um estudo sobre indicadores da educação em bases de dados do INEP. Revista RENOTE. Novas Tecnologias na Educação. CINTED. UFRGS.

PÁDUA, A. F. L. O.; SOUSA, F. A. (2018). Metodologia CRISP-DM: Potencialidades na descoberta do conhecimento em dados educacionais. XVI Congresso Internacional de Tecnologia na Educação. 2018. Disponível em:<http://www.pe.senac.br/congresso/anais/2018/SENAC/pdf/poster>. Acessado em: 25 de março de 2019.

PAIVA, R.; Bittencourt, I. I.; Pacheco, H.; Da Silva, A. P.; Jacques, P.; Isotani, S. (2012). Mineração de dados e a gestão inteligente da aprendizagem: desafios e direcionamentos. Instituto de Computação. Universidade Federal de Alagoas (UFAL). 